\title{
APLICAÇÃO SUPERFICIAL DE DIFERENTES FONTES DE CORRETIVOS NO CRESCIMENTO RADICULAR E PRODUTIVIDADE DA AVEIA PRETA ${ }^{(1)}$
}

\author{
Juliano Corulli Corrêa ${ }^{(2)}$, Leonardo Theodoro Büll ${ }^{(2)}$, Carlos Alexandre \\ Costa Crusciol ${ }^{(2)}$, Dirceu Maximino Fernandes ${ }^{(2)} \&$ Maurício Gomes de \\ Mattos Peres ${ }^{(2)}$
}

\begin{abstract}
RESUMO
Em solos ácidos, a prática da calagem superficial favorece o crescimento radicular, principalmente na superfície do solo, bem como a produtividade das culturas em condições normais de precipitação pluviométrica. Entretanto, pouco se sabe sobre a adoção desta prática e suas eventuais ações, no solo e nas plantas, em relação a outras fontes de corretivos. $O$ objetivo do trabalho foi avaliar o efeito da aplicação superficial de diferentes corretivos nos atributos químicos do solo, no crescimento radicular, da parte aérea e na produtividade da aveia preta. $O$ trabalho foi desenvolvido em campo sobre Latossolo Vermelho distrófico, durante o ano agrícola de 2004, dois anos após a aplicação superficial dos corretivos, no sistema plantio direto. Os tratamentos constituíram da aplicação superficial de calcário dolomítico, escoria de aciaria - E, lama cal - Lcal, lodo de esgoto centrifugado - LC e sem aplicação de corretivo, em delineamento em blocos casualizados com quatro repetições. A aplicação superficial de calcário, escória de aciaria, lama cal, lodo de esgoto centrifugado permitiu o aumento nos valores de $\mathrm{pH}$, no teor de $\mathrm{Ca}$, na maior disponibilidade de $\mathrm{P}$ e na redução dos teores de $\mathrm{Al}$ no solo. $\mathrm{O}$ crescimento do sistema radicular, o desenvolvimento da parte aérea e a produtividade da aveia preta foram incrementados com a aplicação superficial dos corretivos de acidez no sistema plantio direto.
\end{abstract}

Termos de indexação: plantio direto, acidez do solo, correção, Latossolo.

\footnotetext{
(1) Trabalho financiado pela FAPESP. Recebido para publicação em agosto de 2007 e aprovado em março de 2008.

(2) Faculdade de Ciências Agronômicas, Universidade Estadual Paulista - FCA/UNESP. Campus de Botucatu, Caixa Postal 237, CEP 18603-970 Botucatu (SP).E-mails: correajc@superig.com.br; bull@fca.unesp.br, crusciol@fca.unesp.br; dmfernandes@fca.unesp.br
} 


\title{
SUMMARY: SURFACE APPLICATION BY DIFFERENT LIME SOURCE IN ROOT GROWTH AND YIELD OF BLACK OAT
}

\begin{abstract}
Surface lime application to an acid soil under no-till system and normal rainfall conditions increases yield and crop root growth near the soil surface, but the effects of lime sources like flue dust, sewage sludge and aqueous lime have not been fully investigated . The experiment aimed to evaluate the effects of surface application of different lime sources on soil chemical attributes of a clayey, dystrophic Oxisol and black oat root growth and yield under a no-till system. Evaluations were conducted two years after the lime materials were surface-applied. The treatments consisted of surface applications of centrifuged sewage sludge, flue dust, aqueous lime, dolomitic lime and an unlimed control arranged in a randomized complete block design with four replications. Surface application of lime, flue dust, aqueous lime and sewage sludge increased soil $\mathrm{pH}$, exchangeable $\mathrm{Ca}$, resin $\mathrm{P}$ and reduced the exchangeable Al in soil. Black oat root growth, above-ground dry matter and grain yield increased with surface applications of the different lime sources in no-till system.
\end{abstract}

Index terms: No-till, soil acidity, liming, Oxisol.

\section{INTRODUÇÃO}

O crescimento radicular e a produtividade das culturas estão subordinados à característica genética de cada espécie vegetal, entretanto, eles podem ser modificados por fatores químicos e físicos do solo (Rosolem et al., 2000). Vale ressaltar que mais de $70 \%$ dos solos brasileiros são ácidos, o que confere características limitantes ao desenvolvimento da maioria das culturas agrícolas (Quaggio, 2000). Assim, a correção da acidez do solo torna-se imprescindível, uma vez que eleva os teores de Ca e $\mathrm{Mg}$, além de aumentar a disponibilidade de $\mathrm{P}$ e reduzir a de $\mathrm{Al} \mathrm{e} \mathrm{Mn}$ tóxicos no solo, fatores que proporcionam condições favoráveis ao crescimento radicular (Caravalho-Puppatto et al., 2004; Caires et al., 2004, 2006).

Os materiais empregados como corretivos de solo são basicamente os óxidos, hidróxidos, silicatos e carbonatos, capazes de neutralizar a acidez do meio (Alcarde et al., 1992). Além do calcário, outros materiais podem ser utilizados na correção de solos ácidos, e em determinadas situações, são tão eficientes quanto o calcário, ou talvez melhor, principalmente, os que apresentam produtos de dissolução com ânions compostos de silicatos, óxidos e hidróxidos. Esses materiais apresentam maior solubilidade e menor tempo de reação no solo, permitindo não só a correção da acidez do solo de forma mais rápida em comparação ao carbonato de cálcio e magnésio do calcário (Alcarde \& Rodella, 2003), mas também maior lixiviação de sais através do perfil do solo, obtendo, assim, a redução da acidez em subsuperfície, a longo prazo, fato que favorece o crescimento radicular em maiores profundidades (Carvalho-Puppatto, 2004).

O sistema plantio direto eleva os teores de matéria orgânica e nutrientes na superfície do solo (Lovato et al., 2004), fatores que favorecem o crescimento radicular nessas áreas de maior fertilidade. Este fato torna-se ainda mais agravante com a calagem superficial, uma vez que a reação do carbonato de cálcio fica restrito ao local de sua aplicação, graças à baixa solubilidade e ao menor contato das partículas no solo (Amaral et al., 2004; Alleoni et al., 2005). Além disso, em épocas de veranico, esse crescimento superficial das raízes pode-se tornar prejudicial ao desenvolvimento da cultura. Entretanto, em alguns casos a correção da acidez pode ocorrer subsuperfície, (Mello et al., 2003; Caires et al., 2006), mas essa maior eficiência em profundidade depende de fatores, a saber: tipo de corretivo, dosagem, atributos físicos e químicos do solo, regime hídrico de cada região e do manejo das espécies vegetais de cobertura (Alleoni et al., 2005). Assim, a utilização de corretivos que apresentam maior eficiência em neutralizar a acidez em subsolo permitirá maior exploração radicular, uma vez que o impedimento químico do solo é eliminado ou reduzido.

Dentre os principais efeitos benéficos que os corretivos causam à química do solo, vale destacar o aumento no teor de $\mathrm{Ca}$, em razão de não ser ele translocado da parte aérea para as porções mais novas das raízes, devendo estar presente nos locais de crescimento (Caires et al., 2001), bem como a redução na toxidez de Al (Pavan et al., 1982), o qual causa desorganização estrutural das membranas e afeta suas funções, paralisa a síntese de DNA e a mitose, enrijecimento das paredes celulares, redução no alongamento celular e distúrbios na assimilação e no metabolismo mineral nos ápices das raízes (Delhaize \& Ryan, 1995; Peixoto et al., 2007). A aplicação superficial de escória de aciaria, lama cal e lodo de esgoto centrifugado corrigiu a acidez do solo até profundidade $40 \mathrm{~cm}$ (Corrêa et al., 2007). Assim sendo, é de se esperar que os efeitos positivos desses corretivos na fertilidade do solo, principalmente em subsuperfície, promovam maior crescimento radicular e produtividade das culturas. 
O objetivo do trabalho foi avaliar o efeito de diferentes corretivos, dois anos depois da aplicação superficial, nos atributos químicos do solo, no crescimento radicular da parte aérea e na produtividade da aveia preta.

\section{MATERIAL E MÉTODOS}

O experimento foi instalado em campo, durante o ano agrícola de 2004, em área sob sistema plantio direto, na Fazenda Experimental Lageado pertencente à Faculdade de Ciências Agronômicas da UNESP, Botucatu-SP, na latitude de $22^{\circ} 51$ ' 15 ” S, longitude de $48^{\circ} 26^{\prime} 30$ " W e altitude de $740 \mathrm{~m}$. O clima predominante é do tipo $\mathrm{Cwb}$, de acordo com a classificação climática de Köeppen.

O trabalho foi desenvolvido em Latossolo Vermelho distrófico textura média (Embrapa, 1999) manejado no sistema plantio direto. $\mathrm{O}$ solo foi caracterizado quimicamente, antes da instalação do experimento, segundo método descrito por Raij et al. (2001), nas profundidades de $0-5,5-10,10-20$ e $20-40 \mathrm{~cm}$ (Quadro 1).

O delineamento experimental foi em blocos ao acaso com cinco tratamentos e quatro repetições. Os tratamentos foram compostos de calcário dolomítico, lodo de esgoto centrifugado - LC, escória de aciaria E, lama cal - Lcal e uma testemunha - sem aplicação de corretivos. As parcelas tinham $6 \mathrm{~m}$ de largura e $7 \mathrm{~m}$ de comprimento, com $1 \mathrm{~m}$ entre parcelas e $3 \mathrm{~m}$ entre blocos.

As características físicas e químicas dos corretivos foram determinadas segundo método descrito em LANARV (1988) e estão contidas nos Quadros 2 e 3. A dose de cada corretivo foi determinada com base no respectivo PRNT, de modo a elevar a saturação por bases a $60 \%$, na camada de 0-0,20 m (Raij et al., 1996). Assim, utilizaram-se as doses de 2,3, 2,6, 1,7 e $3,5 \mathrm{t} \mathrm{ha}^{-1}$, respectivamente, para os tratamentos com calcário, LC, Lcal e E.

Antes de aplicar os corretivos, realizou-se a dessecação do feijão guandu, cultivado previamente com a finalidade de produzir palhada para o sistema de plantio direto; essa espécie produziu $7.400 \mathrm{~kg} \mathrm{ha}^{-1}$ de matéria seca. Posteriormente, os produtos foram aplicados a lanço (agosto de 2002) sobre a palhada. Foram realizados dois cultivos de soja (2002/2003 e 2003/2004), aplicando-se $300 \mathrm{~kg} \mathrm{ha}^{-1}$ da fórmula 0020-10, sendo as sementes inoculadas com Bradyrhizobium japonicum. Durante o período de inverno (2003 e 2004), cultivou-se aveia preta, cultivar aveia preta comum, utilizando, aproximadamente, 80 sementes por metro e espaçamento de $0,17 \mathrm{~m}$ entrelinhas, com aplicação de $100 \mathrm{~kg} \mathrm{ha}^{-1}$ de uréia no sulco da semeadura.

A amostragem de solo foi realizada após a colheita da aveia preta, 27 meses depois da aplicação dos produtos, coletaram-se amostras nas profundidades de $0-5,5-10,10-20$ e $20-40 \mathrm{~cm}$, utilizando-se trado tipo sonda, recolhendo-se quatro amostras por parcela, para constituir uma amostra composta. Foram analisados $\mathrm{pH}\left(\mathrm{CaCl}_{2}\right), \mathrm{P}$ (resina), $\mathrm{Ca}^{2+} \mathrm{e}^{3}{ }^{3+}$ (Raij et al., 2001).

A avaliação do crescimento e da distribuição do sistema radicular da aveia preta foi realizada no ano de 2004 (fase de emborrachamento). As amostragens foram feitas na entrelinha da cultura, coletando-se três pontos por parcela para constituir uma amostra composta, nas mesmas profundidades da análise química, utilizando-se um trado metálico, tipo sonda, de $80 \mathrm{~cm}$ de altura, raio interno de 7,5 $\mathrm{cm}$ e parede de $0,4 \mathrm{~cm}$. As raízes foram separadas do solo por dispersão em água, usando-se jogo de peneiras sobrepostas, com malha de 0,5 e 0,25 mm. Para avaliar o comprimento e o diâmetro das raízes utilizouse um scanner específico de raízes, adaptado do software Winrhizo 3.8, de acordo com trabalho de Rosolem et al. (2003). Em seguida, essas amostras foram secas em estufa com circulação de ar forçado, na tempertura de $60^{\circ} \mathrm{C}$, durante $48 \mathrm{~h}$; decorrido este intervalo, avaliou-se a massa seca em $\mathrm{g} \mathrm{m}^{-3}$.

Aos 70 DAE, durante o estádio de emborrachamento da aveia preta, foram coletadas todas as plantas presentes em uma área de $0,25 \mathrm{~m}^{2}$ para a determinação da biomassa seca de planta. As plantas foram secas em estufa de circulação de ar forçado à temperatura de $60{ }^{\circ} \mathrm{C}$ durante $48 \mathrm{~h}$. A massa seca foi expressa em kg ha-1.

Quadro 1. Resultados da análise química do solo nas profundidades de 0-5, 5-10, 10-20 e 20-40 cm, antes da instalação do experimento

\begin{tabular}{|c|c|c|c|c|c|c|c|c|c|c|c|}
\hline Profundidade & $\mathbf{p H}$ & MO & $P$ res. & $\mathrm{Al}^{3+}$ & $\mathbf{H}+\mathbf{A l}$ & $\mathbf{K}^{+}$ & $\mathrm{Ca}^{2+}$ & $\mathrm{Mg}^{2+}$ & SB & CTC & V \\
\hline $\mathrm{cm}$ & & $\mathrm{g} \mathrm{dm}^{-3}$ & $\mathrm{mg} \mathrm{dm}{ }^{-3}$ & & 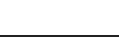 & $-\mathrm{mm}$ & $\mathrm{dm}^{-3}$ & & & - & $\%$ \\
\hline $0-5$ & 4,0 & 16 & 6 & 7 & 38 & 0,6 & 12 & 6 & 19 & 57 & 33 \\
\hline $5-10$ & 4,0 & 18 & 6 & 6 & 45 & 1,0 & 19 & 9 & 29 & 74 & 39 \\
\hline $10-20$ & 4,2 & 15 & 5 & 5 & 45 & 0,7 & 13 & 5 & 19 & 64 & 30 \\
\hline $20-40$ & 3,9 & 10 & 4 & 6 & 42 & 0,6 & 12 & 3 & 16 & 58 & 27 \\
\hline
\end{tabular}


Em 30 de agosto de 2004, foram amostrados os componentes de produção da aveia, coletando-se todas as plantas de uma área correspondente a $0,25 \mathrm{~m}^{2}$ por unidade experimental, avaliando-se número de espigas por $\mathrm{m}^{2}$, número de espiguetas por espiga e peso de 100 sementes; a partir desses dados, estimou-se a produtividade para aveia preta.

Os resultados foram submetidos à análise de variância e as médias comparadas pelo Teste LSD a $5 \%$, sendo as análises realizadas pelo programa Sisvar 4.2 (Ferreira, 2003).

\section{RESULTADOS E DISCUSSÃO}

\section{Atributos químicos do solo}

A aplicação superficial do calcário, escória de aciaria, lama cal e lodo de esgoto centrifugado proporcionou o aumento de $\mathrm{pH}$ do solo e do teor de $\mathrm{Ca}$ trocável, possibilitou a maior disponibilidade de $\mathrm{P} \mathrm{e}$ reduziu o teor de alumínio trocável, após 27 meses de reação (Figuras 1 e 2). No entanto, a eficiência de reação para cada corretivo fica restrita a determinada

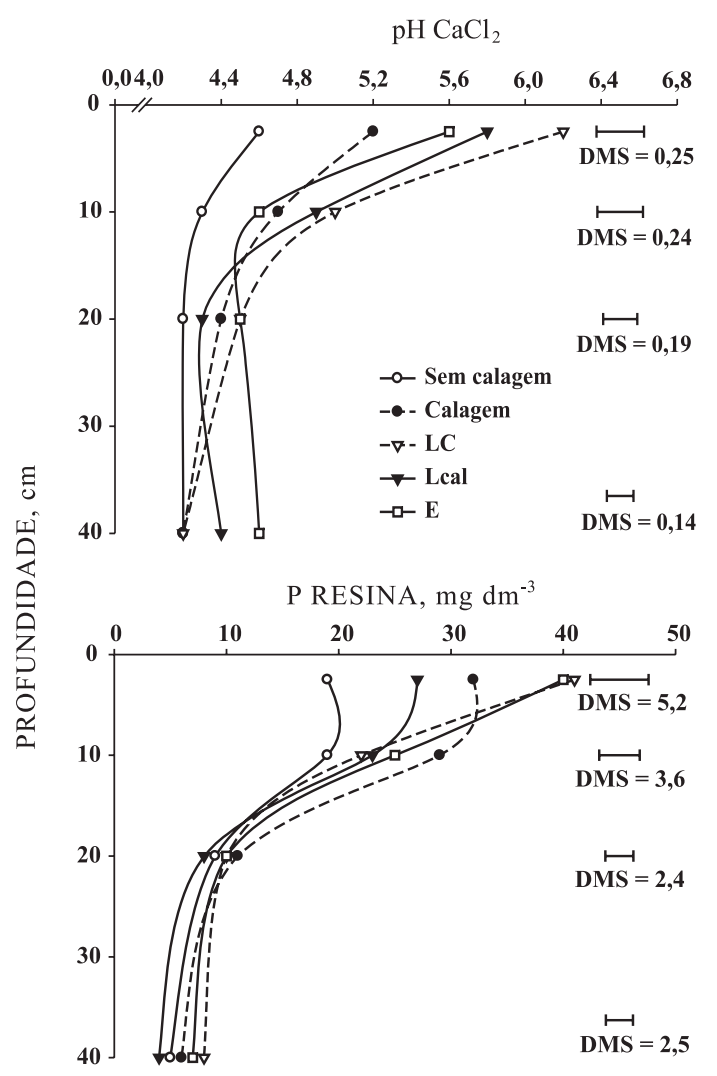

Figura 1. Valores de pH e teores de fósforo disponível no Latossolo Vermelho distrófico em relação à aplicação superficial de diferentes fontes de corretivos da acidez do solo em plantio direto. Barras horizontais representam o Desvio Mínimo Significativo (DMS). profundidade do solo, graças à suas características químicas e granulométricas (Quadros 2 e 3). Vale ressaltar que o aumento da fertilidade do solo nas camadas superficiais de $0-5$ e $5-10 \mathrm{~cm}$ foi mais expressivo quando comparado aos da camadas subsuperficiais de 10-20 e 20-40 cm, o que denota a dificuldade da neutralização da acidez do solo em maiores profundidades em curto prazo.

Com base na análise de variância, o calcário dolomítico e a lama cal apresentaram efeito de correção da acidez do solo até à profundidade de $10 \mathrm{~cm} \mathrm{em}$

Quadro 2. Resultados da análise química dos corretivos

\begin{tabular}{lcccccc}
\hline \multicolumn{1}{c}{ Corretivo } & Umid. & $\mathbf{P}_{2} \mathbf{O}_{5}$ & $\mathbf{K}_{2} \mathbf{O}$ & $\mathbf{N}$ & $\mathbf{C a}$ & $\mathbf{M g}$ \\
& $\mathrm{g} / 100 \mathrm{~g}$ & & & & & \\
& $\mathrm{~g}$ & $100 \mathrm{~g}^{-1}$ & matéria seca & - \\
Lodo de esgoto (LC) & 5 & 2,0 & 0,3 & 2,5 & 28 & 0,4 \\
Lama cal (Lcal) & 19 & 0,2 & 0,1 & 0,4 & 37 & 0,6 \\
Escória (E) & 2 & 1,4 & 0,1 & 0,3 & 23 & 2,1 \\
Calcário & 4 & 0,0 & 0,0 & 0,0 & 20 & 14 \\
\hline
\end{tabular}

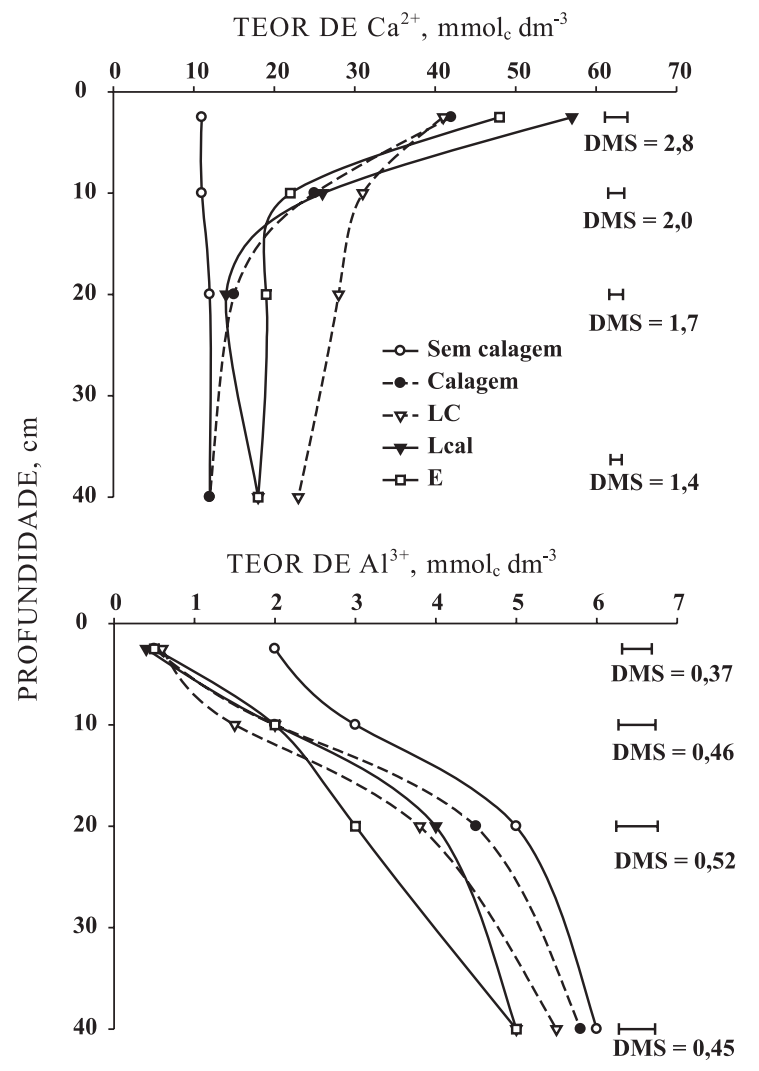

Figura 2. Teores de cálcio e alumínio no Latossolo Vermelho distrófico em relação à aplicação superficial de diferentes fontes de corretivos da acidez do solo em plantio direto. Barras horizontais representam o Desvio Mínimo Significativo (DMS). 
Quadro 3. Distribuição granulométrica de partículas retidas nas peneiras ABNT maior que 10, entre 10-20, entre 20-50 e menor que 50; Reatividade (RE); Poder Neutralizante (PN) e Poder Relativo de Neutralização Total (PRNT)

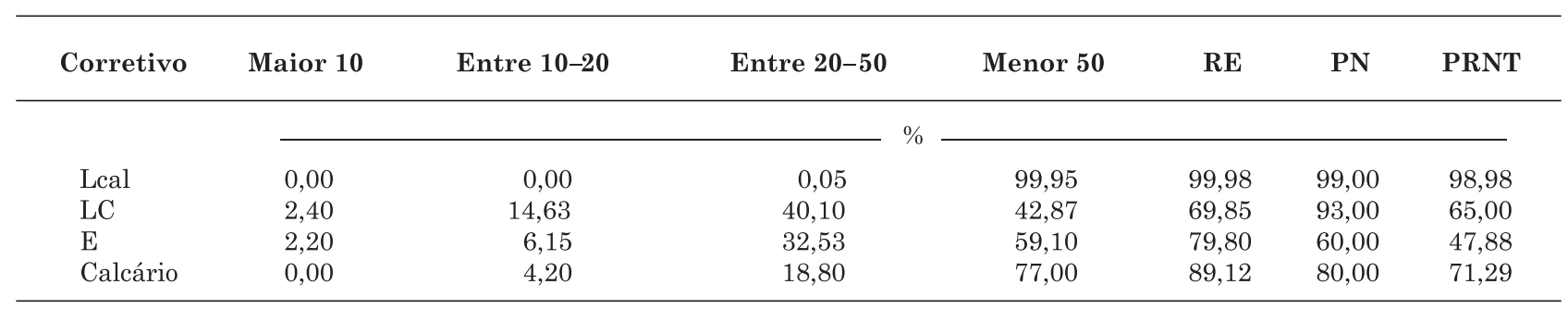

relação ao tratamento sem calagem. Entretanto, o lodo de esgoto centrifugado atuou até à profundidade de $20 \mathrm{~cm}$ e a escória de aciaria até à profundidade de $40 \mathrm{~cm}$ (Figura 1). $\mathrm{O}$ aumento de $\mathrm{pH}$ do solo pela aplicação de lodo de esgoto incorporado foi constatado por Melo et al. (2001) e Oliveira et al. (2002); da mesma forma, a aplicação de escória de aciaria incorporada elevou esse índice de acidez nos trabalhos de Prado \& Fernandes (2003), Carvalho-Pupatto et al. (2004) e Ramos et al. (2006).

Alguns trabalhos têm demonstrado que a reação do calcário, aplicado sobre a superfície do solo, fica restrita ao local da aplicação, isto é, nos primeiros centímetros do solo, decorrente da baixa solubilidade do carbonato de cálcio e do menor contato dessas partículas com o solo (Amaral et al., 2004; Alleoni et al., 2005; Pádua et al., 2006). No entanto, em algumas situações, a reação da calagem superficial pode superar os $10 \mathrm{~cm}$ de profundidade, uma vez que depende de fatores como: tipo de corretivo, dosagem, atributos físicos e químicos do solo, regime hídrico de cada região e do manejo das espécies vegetais de cobertura (Ciotta et al., 2004; Fidalski \& Tormena, 2005; Caires et al., 2006).

A maior eficiência do tratamento E na redução da acidez do solo, até à profundidade de $40 \mathrm{~cm}$ (Figura 1) pode estar ligada à maior quantidade desse corretivo aplicado ao solo (3,5 t ha-1), elevando a quantidade de Ca depositados no solo (805 kg ha-1). Tal fato, possivelmente, permite que esse cátion $\left(\mathrm{Ca}^{2+}\right)$ preencha os lócus de cargas negativas das partículas coloidais do solo e se associe a ânions $\left(\mathrm{OH}^{-}, \mathrm{HCO}_{3}{ }^{-}, \mathrm{NO}_{3}{ }^{-}\right.$e $\left.\mathrm{SiO}_{3}{ }^{-}\right)$, aumentando, assim, o deslocamento dos produtos de dissociação a profundidade maiores, semelhantemente ao que acontece com o calcário (Rheinheimer et al., 2000; Caires et al., 2004). É importante ressaltar que o corretivo E apresenta solubilidade de seis a sete vezes maior que a do calcário (Alcarde, 1992).

Verificou-se maior disponibilidade do $\mathrm{P}$ no solo, principalmente nas camadas superficiais do solo, de 0-5 e 5-10 cm e com menor intensidade nas camadas de 10-20 e 20-40 cm, de acordo com a aplicação dos diferentes corretivos (Figura 1). Dentre os corretivos que se sobressaíram no aumento da disponibilidade de $\mathrm{P}$ no solo estão a $\mathrm{E}$ e o LC, na camada de $0-5 \mathrm{~cm}$.
Essa maior eficiência deve-se ao fato de eles proporcionarem acréscimo de 21,4 e $22,7 \mathrm{~kg} \mathrm{ha}^{-1} \mathrm{de}$ $\mathrm{P}$, o que corresponderia a 42,8 e $45,4 \mathrm{mg} \mathrm{dm}^{-3}$ de $\mathrm{P}$, levando em consideração que esse nutriente se mantivesse apenas na superfície. O calcário mostrou efeito favorável na disponibilização de $\mathrm{P}$ no solo, principalmente na camada de $5-10 \mathrm{~cm}$, sendo essa melhor eficiência semelhante à do tratamento E, nesta mesma camada.

O aumento de fósforo disponível no solo com a aplicação de lodo de esgoto foi demonstrado por vários trabalhos (Berton et al., 1997, Silva et al., 1998; Nascimento et al., 2004; Galdo et al., 2004), fato atribuído à diminuição da adsorção do elemento ao solo. A matéria orgânica possui íons orgânicos que competem com o fosfato pelos sítios de adsorção, e formam complexos e quelatos, aumentando assim sua disponibilidade de P (Hue, 1995). Aumento no teor de $\mathrm{P}$ pela aplicação de escória de aciaria foi encontrado no trabalho de Prado et al. (2002).

O teor de $\mathrm{Ca}$ apresentou comportamento semelhante ao $\mathrm{pH}$ do solo, tendo os corretivos LC, Lcal e E aumentado esse teor de cálcio até a profundidade de $40 \mathrm{~cm}$, enquanto o calcário ficou restrita à profundidade de $20 \mathrm{~cm}$ (Figura 2). Esses resultados corroboram os de Caires et al. (2004), Ciotta et al. (2004) e Fidalski \& Tormena (2005) para a aplicação de calcário sobre a superfície do solo.

A aplicação superficial dos corretivos reduziu a acidez trocável até à profundidade de $40 \mathrm{~cm}$ para os resíduos E e Lcal, até $20 \mathrm{~cm}$ para o LC e de $10 \mathrm{~cm}$ para a calagem (Figura 2). Melo \& Marques (2000) e Oliveira et al. (2002) obtiveram redução no teor de $\mathrm{Al}^{3+}$ no solo com aplicação de lodo de esgoto, enquanto Prado \& Fernandes (2003) e Carvalho-Pupatto (2004) demonstraram a redução desse elemento no solo para a escória de aciaria.

\section{Crescimento radicular e produtividade da aveia preta}

A aplicação dos corretivos causou diferença no comprimento e na massa radicular (Figura 3). Os tratamentos LC, Lcal e E aumentaram o comprimento radicular na aveia preta, especialmente, nas camadas de 0-5 e 5-10 cm e o calcário na de 5-10 cm (Figura 3). 
COMPRIMENTO RADICULAR, $\mathrm{km} \mathrm{m}^{-3}$

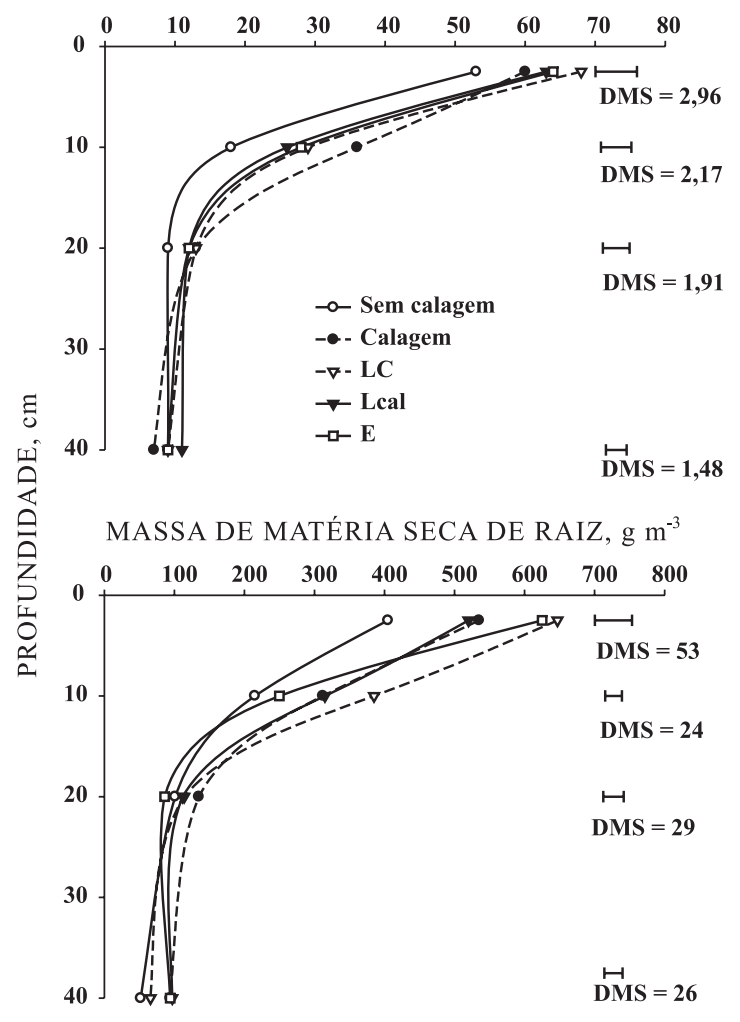

Figura 3. Comprimento radicular e massa de matéria seca de raiz na aveia preta em relação à aplicação superficial de diferentes fontes de corretivos da acidez do solo em plantio direto. Barras horizontais representam o Desvio Mínimo Significativo (DMS).

A dose zero conduziu ao menor comprimento radicular em todas as camadas. O maior crescimento obtido nos tratamentos LC, Lcal e E pode ser atribuído à elevação nos teores de $\mathrm{Ca}$ no solo, aumento do $\mathrm{pH}$, maior disponibilidade de $\mathrm{P}$ e redução do teor de $\mathrm{Al}$ (Figuras 1 e 2), uma vez que as raízes das plantas têm seu crescimento limitado em subsolos ácidos (Pavan et al., 1982), o que interfere na absorção de água e nutrientes e, conseqüentemente, na produtividade das culturas.

Tanto o Ca como o Mg participam do crescimento radicular pela formação de pectatos de Ca e $\mathrm{Mg}$ que compõem a parede celular (Malavolta, 1997). A presença de Ca na solução em contato com as raízes é essencial para a sua sobrevivência, pois não há a translocação do nutriente da parte aérea para as porções novas das raízes em crescimento (Caires et al., 2001).

$\mathrm{Na}$ camada de $20-40 \mathrm{~cm}$, as diferenças entre os tratamentos, apesar de pequenas, são significativas (Figura 3), permitindo inferir sobre a maior exploração de água e nutrientes, principalmente no tratamento Lcal. A importância do sistema radicular profundo reside fundamentalmente na aquisição da água, pois a maior parte da quantidade de nutrientes absorvidas por elas é proveniente das camadas mais superficiais, com especial ênfase para os corretivos aplicados na superfície do solo.

A massa seca de raízes foi incrementada de forma significativa em todas as camadas do solo com a aplicação dos corretivos (Figura 3). Este comportamento pode ser explicado por meio do comprimento radicular, uma vez que a variável diâmetro não apresentou diferença entre os tratamentos.

As camadas do solo que apresentaram maior quantidades de massa radicular foram as de 0-5 e 5$10 \mathrm{~cm}$, profundidades em que se destacaram todos os corretivos. Nas camadas de 10-20 e 20-40 cm a massa radicular foi também diferente entre os tratamentos: calcário, LC e E que causaram maior crescimento na camada de 10-20 cm, e Lcal, E e calcário na de 20 $40 \mathrm{~cm}$. A maior quantidade de raiz em épocas de veranico e com baixa quantidade de alguns nutrientes torna-se fator fundamental no diagnóstico de sistema de manejo para a otimização da produtividade agrícola da cultura em questão e da cultura em sucessão, considerando a formação de bioporos nestas camadas.

A massa seca da parte aérea da aveia preta foi incrementada com prática da aplicação de todos os corretivos na superfície do solo no sistema de plantio direto (Figura 4). O maior crescimento da parte aérea proporcionada pelos corretivos também pode ser justificado pela melhoria dos atributos químicos do solo (Figuras 1 e 2), fato que favoreceu o crescimento

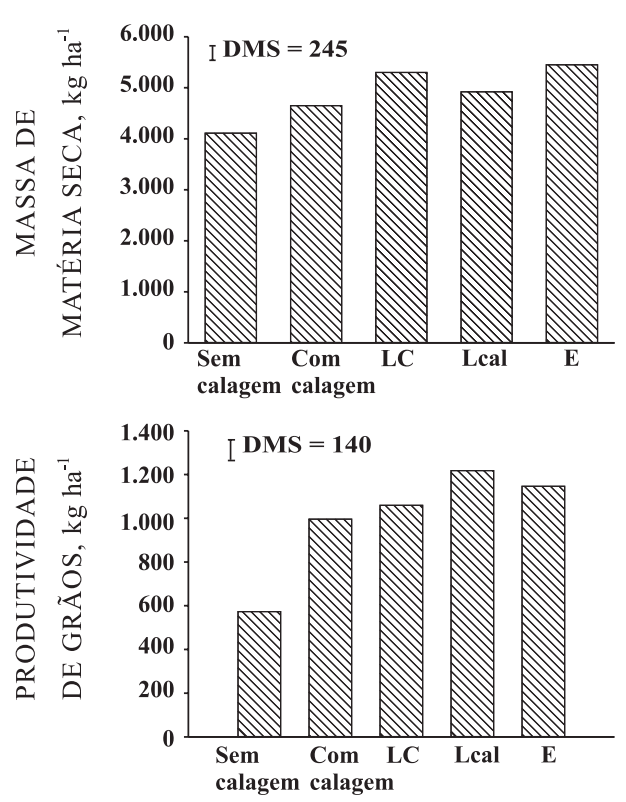

Figura 4. Massa de matéria seca parte aérea e produtividade da aveia preta em relação à aplicação superficial de diferentes fontes de corretivos da acidez do solo em plantio direto. Barras verticais representam o Desvio Mínimo Significativo (DMS). 
radicular, principalmente em subsuperfície (Figura 3), permitindo, assim, a exploração de maior volume do solo para absorção de água e nutrientes pelas plantas, em especial para os corretivos escória de aciaria e lodo de esgoto centrifugado.

A aplicação superficial dos corretivos proporcionou o aumento da produtividade da aveia preta, embora não tenha havido diferença entre eles (Figura 4). A maior produtividade da aveia preta resultante da correção da acidez do solo deveu-se à melhoria das condições para o crescimento das raízes (Figuras $1 \mathrm{e}$ 2), principalmente nas profundidades entre 10 e $40 \mathrm{~cm}$ (Figura 3).

\section{CONCLUSÕES}

1. A aplicação superficial de calcário, escória de aciaria, lama cal e lodo de esgoto centrifugado permitiu o aumento nos valores de $\mathrm{pH}$, nos teores de Ca e de $\mathrm{P}$ e a redução dos teores de $\mathrm{Al}$ no solo.

2. O crescimento do sistema radicular e da parte aérea da aveia preta foram incrementados com a aplicação superficial dos corretivos de acidez no sistema plantio direto.

\section{LITERATURA CITADA}

ALCARDE, J.C. Corretivos da acidez dos solos: características e interpretações. São Paulo, ANDA, 1992. (Boletim Técnico, 6)

ALCARDE, J.C. \& RODELLA, A.A. Qualidade e legislação de fertilizantes e corretivos. In: CURI, N.; MARQUES, J.J.; GUILHERME, L.R.G.; LIMA, J.M.; LOPES, A.S. \& ALVAREZ V.,V.H. eds. Tópicos em ciência do solo. Viçosa, MG, Sociedade Brasileira de Ciência do Solo, 2003. p.291334

ALLEONI, L.R.F.; CAMBRI, M.A. \& CAIRES, E.F. Atributos químicos de um Latossolo de Cerrado sob plantio direto de acordo com doses e formas de aplicação de calcário. R. Bras. Ci. Solo, 29:923-934, 2005.

AMARAL, A.S.; ANGHINONI, I. \& DESCHAMPS, F.C. Resíduos de plantas de cobertura e mobilidade dos produtos da dissolução do calcário aplicado na superfície do solo. R. Bras. Ci. Solo, 28:115-123, 2004.

BERTON, R.S.; VALADARES, J.M.A.S.; CAMARGO, O.A. \& BATAGLIA, O.C. Peletização de biossólidos e adição de $\mathrm{CaCO}_{3}$ na produção de matéria seca e absorção de $\mathrm{Zn}, \mathrm{Cu}$ e Ni pelo milho em três Latossolos. R. Bras. Ci. Solo, 21:685-691, 1997.

CAIRES, E.F.; CORRÊA, J.C.L.; CHURKA, S.; BARTH, G. \& GARBUIO, F.J. Surface application of lime ameliorates subsoil acidity and improves root growth and yield of wheat in an acid soil under no-till system. Sci. Agric., 63:502509, 2006.
CAIRES, E.F.; FELDHAUS, I.C. \& BLUM, J. Crescimento radicular e nutrição da cevada em função da calagem e aplicação de gesso. Bragantia, 60:213-223, 2001.

CAIRES, E.F.; KUSMAM, M.T.; BARTH, G.; GARBUIO, F.G. \& PADILHA, J.M. Alterações químicas do solo e resposta do milho à calagem e aplicação de gesso. R. Bras. Ci. Solo. 28:125-136, 2004.

CARVALHO-PUPPATTO, J.G.; BÜLL, L.T. \& CRUSCIOL, C.A.C. Atributos químicos do solo, crescimento radicular e produtividade do arroz com a aplicação de escórias. Pesq. Agropec. Bras., 39:1213-1218, 2004.

CIOTTA, M.N.; BAYER, C.; ERNANI, P.R.; FONTOURA, S.M.V.; WOBETO, C. \& ALBUQIERQUE, J.A. Manejo da calagem e os componentes da acidez de Latossolos Bruno em plantio direto. R. Bras. Ci. Solo, 28:317-326, 2004.

CORRÊA, J.C.; BÜLL, L.T.; CRUSCIOL, C.A.C.; MARCELINO, R. \& MAUAD, M. Correção da acidez e mobilidade de íons em Latossolo com aplicação superficial de escória, lama cal, lodos de esgoto e calcário. Pesq. Agropec. Bras., 42:1307-1317, 2007.

DELHAIZE, E. \& RYAN, P.R. Aluminum toxicity and tolerance in plants. Plant Physiol., 107:315-321, 1995.

EMPRESA BRASILEIRA DE PESQUISA AGROPECUÁRIA EMBRAPA. Sistema brasileiro de classificação de solos. Brasília, Embrapa Produção de Informação; Rio de Janeiro, Embrapa Solos, 1999. 412p.

FERREIRA, D.F. SISVAR versão 4.2. Lavras, Universidade Federal de Lavras, 2003.

FIDALSKI, J. \& TORMENA, C.A. Dinâmica na calagem superficial em um Latossolo Vermelho distrófico. R. Bras. Ci. Solo, 29:235-247, 2005.

GALDO, M.V.; DE MARIA, I.C. \& CAMARGO, O.A. Atributos químicos e produção do milho em um Latossolo Vermelho eutroférrico tratado com lodo de esgoto. R. Bras. Ci. Solo, 28:569-577, 2004

HUE, N.V. Sewage sludge. In: RECH, G.L., eds. Soil amendments and envioronmental quality. Boca Raton, CRC Press, 1995. p.149-168.

LABORATÓRIO NACIONAL DE REFERÊNCIA VEGETAL LANARV. Análise de corretivos, fertilizantes e inoculantes: métodos oficiais. Brasília, 1988. 104p.

LOVATO, T.; MIELNICZUK, J.; BAYER, C. \& VEZZANI, F. Adição de carbono e nitrogênio e sua relação com os estoques no solo e com o rendimento do milho em sistemas de manejo. R. Bras. Ci. Solo, 28:175-187, 2004.

MALAVOLTA, E.; VITTI, G.C. \& OLIVEIRA, S.A. Avaliação do estado nutricional de plantas: princípios e aplicações. 2.ed. Piracicaba, Potafos, 1997. 319p.

MELLO, J.C.A.; VILLAS-BOAS, R.L.; LIMA, E.V.; CRUSCIOL, C.A.C. \& BÜLL, L.T. Alterações nos atributos químicos de um Latossolo Dristroférrico decorrentes da granulometria e doses de calcário em sistemas plantio direto e convencional. R. Bras. Ci. Solo, 27:553-561, 2003. 
MELO, W.J. \& MARQUES, M.O. Potencial do lodo de esgoto como fonte de nutrientes para as plantas. In: BETTIOL, W. \& CAMARGO, O.A., eds. Impacto ambiental do uso agrícola do lodo de esgoto. Jaguariúna, Embrapa Meio Ambiente, 2000. p.109-141.

MELO, W.J.; MARQUES, M.O. \& MELO, V.P. O uso agrícola do biossólido e as propriedades do solo. In: TSUTIYA, M.T.; COMPARINI, J.P.; SOBRINHO, P.A.; HESPANHOL, I.; CARVALHO, P.C.T.; MELFI, A.J.; MELO, W.J. \& MARQUES, M.O. Biossólidos na agricultura. São Paulo, SABESP, 2001. 468p.

NASCIMENTO, C.W.A.; BARROS, D.A.S.; MELO, E.E.C. \& OLIVEIRA, A.B. Alterações químicas em solos e crescimento de milho e feijoeiro após aplicação de lodo de esgoto. R. Bras. Ci. Solo, 21:385-392, 2004.

OLIVEIRA, F.C.; MATTIAZZO, M.E.; MARCIANO, C.R. \& ROSSETO, R. Efeito das aplicações sucessivas de lodo de esgoto em Latossolo Amarelo distrófico cultivado com cana de açúcar: carbono orgânico, condutividade elétrica, $\mathrm{pH}$ e CTC. R. Bras. Ci. Solo, 26:505-519, 2002.

PÁDUA, T.R.P.; SILVA, C.A. \& MELO, L.C.A. Calagem em Latossolo sob influência de coberturas vegetais: neutralização da acidez. R. Bras. Ci. Solo, 30:869-878, 2006.

PAVAN, M.A.; BINGHAM, F.T. \& PRATT, P.F. Toxicity of aluminum to coffee (Coffea arabica L.) in Ultisols and Oxisols amended with amended with $\mathrm{CaCO}_{3}, \mathrm{MgCO}_{3}$ and $\mathrm{CaSO}_{4} \cdot 2 \mathrm{H}_{2} \mathrm{O}$. Soil Sci. Soc. Am. J., 46:1201-1207, 1982.

PEIXOTO, P.H.; PIMENTA, D.S. \& CAMBRAIA, J. Alterações morfológicas e acúmulo de compostos fenólicos em plantas de sorgo sob estresse de alumínio. Bragantia, 66:17-25, 2007.

PRADO, R.M. \& FERNANDES, F.M. Efeito residual da escória de siderurgia como corretivo da acidez do solo na soqueira da cana de açúcar. R. Bras. Ci. Solo, 27:287-296, 2003.
PRADO, R.M.; COUTINHO, E.L.M.; ROQUE, C.G. \& VILLAR, M.L. Avaliação da escória de siderurgia e de calcário como corretivo da acidez do solo no cultivo do alface. Pesq. Agropec. Bras., 37:339-546, 2002.

QUAGGIO, J.A. Acidez e calagem em solos tropicais. Campinas, Instituto Agronômico, 2000. 111p.

RAIJ, B.van.; CANTARELlA, H.; QUAGGIO, J.A. \& FURLANI, A.M.C. Recomendações de adubação e calagem para o Estado de São Paulo. 2.ed. Campinas, Instituto Agronômico \& Fundação IAC, 1996. 285p. (Boletim Técnico, 100)

RAIJ, B.van; ANDRADE, J.C.; CANTARELLA, H. \& QUAGGIO, J.A. Análise química para avaliação da fertilidade de solos tropicais. Campinas, Instituto Agronômico, 2001. 285p.

RAMOS, L.A.; NOLLA, A.; KORNDÖRFER, G.H.; PEREIRA, H.S. \& CAMARGO, M.S. Reatividade de corretivos da acidez e condicionadores de solo em colunas de lixiviação. R. Bras. Ci. Solo, 30:849-857, 2006.

RHEINHEIMER, D.S.; SANTOS, E.J.S.; KAMINSKI, J.; BORTOLUZZI, E.C. \& GATIBONI, L.C. Alterações de atributos do solo pela calagem superficial e incorporada a partir de pastagem natural. R. Bras. Ci. Solo, 24:797-805, 2000 .

ROSOLEM, C.A.; GIOMMO, G.S. \& LAURENTI, R.L.B. Crescimento radicular e nutrição de cultivares de algodoeiro em resposta à calagem. Pesq. Agropec. Bras., 35:827-833, 2000.

ROSOLEM, C.A.; SILVA, R.H. \& ESTEVES, J.A.F. Potassium supply to cotton roots as affected by potassium fertilization and liming. Pesq. Agropec. Bras., 38:635-641, 2003.

SILVA, F.C.; BOARETT, A.E.; BERTON, R.S.; ZOTELLI, H.B.; PEIXE, C.A. \& MENDONÇA, E. Cana de açúcar cultivada em solo adubado com biossólido. Pesq. Agropropec. Bras., 33:1-8, 1998. 